DOI: https://doi.org/10.3126/jbssr.v5i2.35230

\title{
Impact of COVID-19 on Nepalese Small and Medium Enterprises
}

\author{
Jeetendra Dangol ${ }^{1}$ \\ Sunil Chitrakar ${ }^{2}$ \\ Kee-Seon $\mathrm{Yoo}^{3}$
}

Article History

Received 22 Oct 2020

Reviewed 25 Nov 2020

Revised 28 Nov 2020

Plagiarism Checked

5 Dec 2020

Revised 10 Dec 2020

Accepted 15 Dec 2020

Keywords

business challenges,

COVID-19, firm's

response, government

and social response

Journal of Business and

Social Sciences Research

(ISSN: 2542-2812). Vol V,

No. 2, Dec 2020

\section{Abstract}

This study seeks to explore the impact of COVID-19 on Nepalese SMEs. This study is based on 41 respondents from Nepalese SMEs, conducted in the first two weeks of August 2020. The questionnaires are developed in 4-point Likert scale on five major areas: current business challenges, firm's respond to COVID-19, social response, SMEs' perception on post COVID-19 and government's response to COVID-19. The questionnaires are pretested for content validity and found internal consistency of instruments. The study used mean, standard deviation, and match t-test. The Nepalese SMEs give importance to social response, followed by firm's response to COVID-19 and current business challenges. However, Nepalese SMEs are unsatisfied with the government's response to COVID-19 and the role of government is inevitable in safeguarding SMEs.

\section{Introduction and Study Objectives}

Small and medium sized enterprises (SMEs) accounts for two-third of the global jobs and half of its GDP (Gibbens, 2020). In Nepalese context, 99\% of registered enterprises are micro, small and medium enterprises and $95 \%$ of employment are created by this sector (Central Bureau of Statistics, 2019). The role of SMEs is significant as it creates jobs, mobilizes local resources and creates wealth. The business performance of this sector has a large impact on the overall

${ }^{1}$ Dr Dangol is Associate Professor, Faculty of Management, Tribhuvan University, Nepal. His email is jdangol@gmail.com

${ }^{2}$ Dr Chitrakar is CEO of Mahaguthi Craft With Conscience, as well as Visiting Faculty at Nepal Open University. His email is sunilchitrakar@hotmail.com

${ }^{3}$ Dr. Yoo is Professor and Dean of School of Management and Economics at Hangdong Global University, Republic of Korea. He can be contacted at ksyoo@handong.edu 
economic performance of the country. The rapid spread of COVID-19 has put a halt in Nepalese economic activities as the government imposed strict lockdown in March 2020. It has devastating effects on Nepalese SMEs, as they are less equipped with strategies and resources to cope with crises (UNDP, 2020, OCED, 2020).

According to the World Health Organisation (2020), by mid-August 2020, the COVID-19 has caused over 720,000 human casualties and catastrophic economic crisis in 216 countries around the world. Over the last six months, the world has witnessed massive economic shutdowns causing effects on personal healthcare, social lives, employment, businesses and the overall economy. Entire global supply chain has been on halt, which has disrupted consumptions, business continuity and overall global growth. This shock wave has gone through Nepalese economy as well.

After the reopening of economies, the cases of COVID-19 have dramatically increased so as the mortality rate. The local and federal governments are imposing different measures to tackle the situation with little success. Amidst COVID-19, Nepal government estimated only 2.5\% GDP growth for the year 2020 (MOF, GON, 2020), whereas the World Bank (2020) has revised its forecast and predicted only $1.8 \%$ for the fiscal year 2020. UNDP (2020) has estimated that accommodation and food (include tourism, hotels), arts, entertainment, recreation and transportation are the most affected whereas, manufacturing, construction, wholesale, retail trade and agriculture are affected moderately. Despite the reopening, the economic activities are still very slow as international flights are still closed, imports and exports are minimal, the tourism sector is completely closed; and retail stores are deserted, and remittance dropped. UN reports estimated that 3.5 million people are engaged in enterprise sectors and among them 59 per cent are micro enterprises. This crisis disproportionately affects most vulnerable groups of Nepalese society such as women, elderly and marginalized communities (UNDP, 2020).

The private sector representative organisations have been very vocal on demanding stimulus plans to help the private sector get back to business. The Government of Nepal has responded to COVID-19 through its budgetary policies. The Nepal Government has assigned a special low interest (5\%) loan fund of 42 million USD in its fiscal plan for FY 2020/21. Likewise, it has provisioned 84 million USD for refinancing at $5 \%$ interest as an economic stimulus plan. It also has provisioned for skill development, strengthening domestic industries by enhancing productivity and employment promotion. The policy also focused on providing some subsidies on interest and loan schedules and availability of credits to SMEs.

Private sectors in Nepal have been cooperating with the government in the fight against COVID-19. They kept their businesses closed and tried to retain their workers by paying as much they can for the period of lockdown. Nepalese SMEs 
have demonstrated resilience while fighting against COVID-19, they have very little support from the government.

Nepalese economy and business have witnessed a catastrophic impact of the pandemic. Amidst the pandemic, this study carried out to assess the impact of COVID-19 on Nepalese SMEs and assess the degree of their resilience to fight with the challenges posed by this crisis. It explored how they responded to the crisis, the major challenges and opportunities they have faced.

The next section states the objectives of the paper. Section three reviews the literature on the subject. The methodology of the study is discussed in the fourth section. The fourth and fifth sections present the results and conclusions respectively. The last section provides the implications.

$>$ To assess the impact of COVID-19 on the Nepalese SMEs;

$>$ To examine the challenges and opportunities for Nepalese SMEs;

$>$ To assess Nepalese SMEs' responses to COVID-19

\section{Literature Review}

The pandemic has affected SMEs in both demand and supply side (OCED, 2020). SMEs experienced shortage of labour forces and shortages of needed raw materials in the supply side, whereas sudden loss of demand and revenue in demand side. Nepalese SMEs with limited infrastructure development and weaker logistic management have faced the challenges of meeting the customer demand and maintaining the supply chain (Shrestha, 2020). This has a big impact on SMEs' cash flow, loss of customers and revenue, and may eventually shut down business in future. Consumer confidence dropped as their focus shifted to primary healthcare and safety and their loss of income resulted in a steady decline in consumption (IMF, 2020). Despite the reopening of business, SMEs are vulnerable in terms of occupational safety and health conditions and find it difficult to maintain social distancing and safety measure as their existing business model, systems and resources are simply not enough (Prasain \& Pradhan, 2020).

World Bank, (2020) stated that the COVID-19 has profound consequences on Nepalese business and economy, which leads to new business model to come. It is likely that Nepalese economy and business will look inward as export has shrunken and foreign employment opportunities declined. Digitization is taking headways in Nepalese market with start-ups companies. Green growth will be good for sustainable economic recovery while increase in vulnerability and inequality. The World Economic Forum (2020) argued that the COVID-19 pandemic is exposing the systemic inequalities of the global economic system, and threatening progress towards equality and advancement of human rights. 
The Government of Nepal has responded COVID-19 with four measures; immediate relief program, reduce the impact of COVID-19, economic support measures and liquidity support measures through its fiscal and monetary policies (World Bank, 2020). The government has launched an economic support package that includes deferred payment on tax, concession on interest rate payment and utility payments that cost about $5 \%$ of the GDP (World Bank, 2020).

Despite the government's fiscal and monetary policy to curb the short-term and mid-term impact of COVID-19 on Nepalese economy, SMEs are not likely to be benefited as businesses fail to generate businesses as demand for nonessentials goods and services have not increased.

While most of the SMEs reported loss of sales, some SMEs who rely on digital technologies reported increase in sales during the pandemic (OCED, 2020). Increasing number of platform businesses in Nepalese market (e.g., Daraz, Kirana, Sastodeal, Foodmandu, Bhojdeal, Hamrobazar, Muncha, NepBay, SmartDoko, Metrotarkari) have positive impact on increasing sales and expansion of businesses. There was an increase in use of mobile technology and digitization during the pandemic. There is acceleration in use of mobile technology in trade of goods and services, social interaction, public services and entertainments (World Bank, 2020). Nepali Times (2020) reported an increase in internet users by $35 \%$ over the last four months during the lockdown. These businesses are expected to grow, as more SMEs will look for ways to improve their sales through these new opportunities (Shrestha, 2020). Emergence of digital technologies provides opportunities for SMEs to enhance their reach, cost efficiency and enhance their competitiveness (Rajagopaul, Magwentshu, \& Kalidas, 2020). SMEs can build resilience to foster their businesses and build a buffer for any crisis as such. They can improve their resilience by building leadership resilience (building strong team), revenue resilience (shifting revenue stream), organisational resilience (building robust organisation), financial resilience (having firm grip on money) and operational resilience (streamlining supply chain) (Isenberg, Onyemah, \& Mulcahy, 2020).

Shrestha (2020) opined that the emergence of sustainable organisations with empathic leaders to tackle the challenges and opportunities presented by the pandemic is inevitable. Leaders should have the ability to take proactive actions, risk-taking attitudes and innovativeness. Leadership quality comes into play while dealing with the crisis; building strong teams, engaging people and networks. The business leaders need to assess the situation, visualise the business environment, and make quick response to the situation to minimise the negative impact and recover from the crisis. Further, Shrestha (2020) explained that sustainability will emerge and revolutionise post COVID-19 entrepreneurial ecosystem as a resilient and sustainable organisation.

Likewise, OCED (2020) reported a host of stimulus plans offered to SMEs in different countries under different incentives and provisions such as labour 
redundancy, working hour alteration, deferral payment schemes, waiving utility bill payments, lower interest loans, grants and subsidies, structural reforms, and capacity building programs.

Nepalese SMEs have survived through decade long civil war, political uncertainties, earthquakes and blockade. They have found their ways to survive those challenging years. This COVID-19 crisis poses greater threat as it has affected all the sectors. SMEs need support from the government and other agencies at the same time, they need to come up with strategies to find new market opportunities within Nepal and abroad. This study has attempted to understand the challenges that Nepalese SMEs are facing amidst COVID-19 and to assess how they are responding to it.

\section{Research Methods}

This is exploratory research aimed to explore the responses of Nepalese SMEs on COVID-19 and its impact on their businesses. This study has used primary data generated from a questionnaire survey. The questionnaire was designed to achieve the objectives of the study, which included respondents' brief profiles, their perception on impact of COVID-19 on their business, their responses to it and their future perspective amidst the pandemic. It was measured using a 4-point Likert scale. The questionnaire was pre-tested with a small sample size of three MBA students. These procedures were designed to strengthen content validity and reduce the contaminating influence of certain response sets.

The research instrument comprises of 43 items in 5 dimensions, i.e., Current business challenges (6 items), Firm's response to COVID-19 (14 items), Social response (9 items), SMEs' perception on post COVID-19 (9 items), and Government's response to COVID-19 (5 items).

For each item, respondents were asked to judge on a 4-point Likert scale between strongly disagree/strongly dissatisfaction, disagree/dissatisfaction, agree/satisfaction, and strongly agree/strongly satisfaction, (equal interval scale for which values of 1 to 4 , respectively, were later assigned to conduct data analyses). Table 1 shows a list of 43 items in the same sequence as given in the survey.

Questionnaire was prepared using Google Form and circulated through emails. The respondents were selected using judgmental sampling criteria. The list of potential respondents was collected through Fair Trade Group Nepal, Federation of Women Entrepreneurship Nepal, and Federation of Handicraft Association of Nepal. The respondents have to be SMEs as classified in Industrial Enterprise Act 2016 (Government of Nepal, 2016) and must have been operating over 5 years. Total 125 questionnaires were circulated electronically between August $1^{\text {st }}$ and $15^{\text {th }}, 2020$. All together 41 respondents have responded to the questionnaire; the response rate was 32.80 percent. 
Reliability has to do with the accuracy and precision of a measurement procedure to test internal consistency of the questionnaire constructs. Reliability test was carried out using Cronbach's alpha test method. Cronbach's alpha is 0.703 for 43 statements, indicating good internal consistency.

\section{Data Analysis and Results}

Table 1 presents frequencies, means, and ranks for the 43 statements of the questionnaire.

\section{Current Business Challenges}

First six items are related with the current business challenges faced by the SMEs in Nepal due to COVID-19. The majority of the respondents $(75.70 \%)$ are facing the problem of loss of sales order (item 2; ranked 9; mean value 2.90). On the contrary, $75.60 \%$ of the respondents expressed they have less challenges of shortage of workers at the moment. Likewise, $70.70 \%$ of respondents opined that the supply chain has been disrupted (item; ranked 14; mean 2.73). There is an average effect on liquidity problems (item 1; ranked 21; mean), loss of business network (item 4; ranked 29) and not able to pay liabilities (item 6; ranked 25).

\section{Firm's Response to COVID-19}

This section of the questionnaires deals on the measures that SMEs are taking in response to COVID-19. Majority of the respondents $(95.1 \%)$ said they discuss regularly with their staff to overcome the current problem (item 19; ranked 1 ; mean 3.44). Two-third of the respondents are not considering laying off their workers as they least prioritized it (item 7 ; rank 39). Despite the challenges, $36.6 \%$ of the firms are paying full salaries to their workers (item 8; rank 16) and the majority of them $(95.1 \%)$ are engaging in COVID-19 prevention measures (item 18; ranked 2; mean 3.37). It demonstrates that Nepalese SMEs are resilient in this crisis and are doing their best to stay afloat. In response to the crisis $87.88 \%$ respondents opined that they are strengthening their supply chain management (item 20; rank 7 ), which is important strategic move to survive beyond COVID-19 and SMEs need to improve operational efficiencies (Isenberg, Onyemah, \& Mulcahy, 2020).

Four-fifth of the respondents engaged in strengthening customer relationships as they frequently reach out to their customers (item 17; rank 8). Likewise, twothird of the respondents are found developing strategic alliance and networking amidst the pandemic (item 15; rank 17). It indicates that overall supply chain management and customers are placed in the higher priority by Nepalese SMEs.

Around seven-tenth SMEs are paying their liabilities in delay than their scheduled time (item 9; rank 12). They reduce their business operation by three-fifth firms (item 10; rank 18). The two-third firms are thinking for online businesses (item 13 , rank 19) and only one-fifth of the respondents are supposed to change the existing business (item 14; rank 42). It shows that the majority of the SMEs are 
thinking to continue their existing business using advanced technology to sustain in the market. The majority of the respondents (58.50\%) are not willing to take bank loans (item 11; rank 30). It shows that Nepalese SMEs are running the traditional way without taking loans or trying to minimize loan amount.

\section{Social Response}

This section deals with social response, mainly, the labour aspect. It attempts to measure how Nepalese SMEs are handling labour issues during the current pandemic. Four statements, out of nine items, are found within six top ranks. The majority of the respondents (84.4\%) argued that they are paying salaries and wages to their workers regularly (item 25; rank 3 ) even but they are not able to pay additional fringe benefits. Around three-fifth firms (item 26; rank 33) are not able to pay the fringe benefits during the lockdown period. The respondents are able to maintain social distancing at work place by around nine-tenth firms (item 21; rank 4). Interestingly, the nine-tenth of respondents argued that their workers maintained good emotional and physical health (item 27; rank 5) and they are providing flexible work schedules to their workers (item 28; rank 6). Similarly, around three-fifth of the respondents are disinfecting their workplace regularly (item 24; rank 11). All these things are evidence that the Nepalese SMEs are more concerned about their social value delivery towards their employees. As well as the result indicates that Nepalese SMEs are aware of health and safety issues, they are taking good care of their workers, labourers paying them, and maintaining social distancing at work. With limited resources, SMEs cannot redesign the workplace suitable to protect COVID (item 22; rank 26). However, they are keen in operating their businesses with safety measures, they can afford such as providing Personal Protection Equipment (PPE) by $43.90 \%$ firms (item 23; rank 28 ) and COVID insurance to their staffs by $36.60 \%$ firms (item 29 ; rank 34 ).

\section{SMEs' Perception on Post COVID-19}

Nepalese SMEs are found optimistic to some extent as they expect their operation, and their sales will increase after the crisis. Around three-fifth of the respondents opined to change their existing business model (item 35; rank 23) and $53.6 \%$ of SMEs are looking for new business opportunities (item 38; rank 27 ). This opinion is very much supported with their optimism of gaining their sales and operation back. Around half $(48.80 \%)$ of the respondents foresee the increase in sales (item 30; ranked 24; mean 2.51), while $70 \%$ of the respondents believe that their production will increase after the crisis. They seek to increase their workers (item 33; ranked 10; mean 2.9) and workers (item 34, ranked 13; mean 2.78) post pandemic. Likewise, they are expecting the improvement in raw material availability in post pandemic (item 32; rank 20; mean 2.63). Despite their lower expectation of any government support (item 37 ; ranked 41 ; mean 1.93), they have confidence in their pursuit of finding new opportunities and continuing their business. Nepalese SMEs are entrepreneurial oriented, which helped them to stay in the business despite the turbulent times (Chitrakar, 2019). 


\section{Government's Response on COVID-19}

Regarding the government's response to COVID-19, all the five items get mean value lesser than 2.5 and least rank between 35 and 43 , indicating that almost all respondents are not satisfied with the government's response to COVID-19 and the measures it took for business and economic recovery. In this issue, around three-fifth of the respondents are unsatisfied with the announcement of loan repayment extended policy of government (item 39; rank 35). The government also announced subsidizing interest loans (item 40; rank 36) to SMEs, which is also not satisfied by the two-third of the respondents. Similarly, the majority of the respondents $(63.40 \%)$ are not happy with the budget speech for fiscal year 2020/21 (item 41; rank 37) and tax rebate for export (item 43; rank 40). The majority of the respondents $(85.30 \%)$ blame that the government does not initiate to promote SMEs (item 42; rank 43). It shows that Nepalese SMEs are believed that Nepalese government is not taking effective measures to overcome the COVID problems in SMEs.

Table 1

Frequency Distribution, Means, and Ranks of Responses to Questionnaire on COVID-19 Effects

\begin{tabular}{|c|c|c|c|c|c|c|c|}
\hline \multirow{2}{*}{\multicolumn{2}{|c|}{ 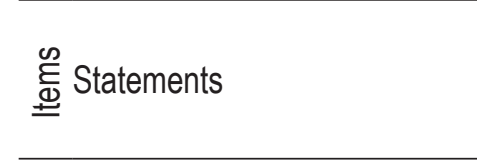 }} & \multicolumn{4}{|c|}{ Percentage of responses ${ }^{*}$} & \multirow{2}{*}{$\begin{array}{l}\text { Mean } \\
\text { (Std. } \\
\text { Deviation) }\end{array}$} & \multirow[b]{2}{*}{ Rank } \\
\hline & & $\begin{array}{l}\text { V. Low } \\
1\end{array}$ & $\begin{array}{l}\text { Low } \\
2\end{array}$ & $\begin{array}{l}\text { High } \\
3\end{array}$ & $\begin{array}{l}\text { V. High } \\
4\end{array}$ & & \\
\hline & Current business challenges & & & & & & \\
\hline 1 & Liquidity problem & 12.2 & 31.7 & 41.5 & 14.6 & $2.59(0.89)$ & 21 \\
\hline 2 & Loss of sales order & 7.3 & 17.1 & 53.7 & 22.0 & $2.90(0.83)$ & 9 \\
\hline 3 & Lack of staffs/workers & 29.3 & 46.3 & 19.5 & 4.9 & $2.00(0.84)$ & 38 \\
\hline 4 & Loss of business network & 22.0 & 29.3 & 41.5 & 7.3 & $2.34(0.91)$ & 29 \\
\hline 5 & Supply chain disruptions & 9.8 & 19.5 & 58.5 & 12.2 & $2.73(0.81)$ & 14 \\
\hline \multirow[t]{3}{*}{6} & $\begin{array}{l}\text { Not able to pay liabilities } \\
\text { (wage, interest, rent, creditors) }\end{array}$ & 12.2 & 39.0 & 36.6 & 12.2 & $2.49(0.87)$ & 25 \\
\hline & & $\begin{array}{l}\text { Strongly } \\
\text { Disagree }\end{array}$ & Disagree & Agree & $\begin{array}{l}\text { Strongly } \\
\text { Agree }\end{array}$ & $\begin{array}{l}\text { Mean } \\
\text { (Std. } \\
\text { Deviation) }\end{array}$ & \\
\hline & Firm's respond to COVID-19 & & & & & & \\
\hline 7 & We lay off staffs & 41.5 & 26.8 & 24.4 & 7.3 & $1.98(0.99)$ & 39 \\
\hline 8 & We pay to staffs partially & 17.1 & 19.5 & 41.5 & 22.0 & $2.68(1.01)$ & 16 \\
\hline 9 & We pay liabilities in delay & 9.8 & 19.5 & 53.7 & 17.1 & $2.78(0.85)$ & 12 \\
\hline 10 & $\begin{array}{l}\text { We reduce our business } \\
\text { operation }\end{array}$ & 7.3 & 34.1 & 46.3 & 12.2 & $2.63(0.80)$ & 18 \\
\hline 11 & We took bank loan & 22.0 & 36.5 & 29.3 & 12.2 & $2.32(0.96)$ & 30 \\
\hline 12 & We clear stocks & 17.1 & 43.9 & 34.1 & 4.9 & $2.27(0.81)$ & 32 \\
\hline 13 & We go online business & 12.2 & 22.0 & 56.1 & 9.8 & $2.63(0.83)$ & 19 \\
\hline
\end{tabular}


Impact of COVID-19 on Nepalese Small and Medium... : Dangol, Chitrakar, Yoo

\begin{tabular}{|c|c|c|c|c|c|c|c|}
\hline & & $\begin{array}{l}\text { Strongly } \\
\text { Disagree }\end{array}$ & Disagree & Agree & $\begin{array}{l}\text { Strongly } \\
\text { Agree }\end{array}$ & $\begin{array}{l}\text { Mean } \\
\text { (Std. } \\
\text { Deviation) }\end{array}$ & \\
\hline 14 & We change the business & 39.0 & 41.5 & 17.1 & 2.4 & $1.83(0.80)$ & 42 \\
\hline & $\begin{array}{l}\text { We developed networking and } \\
\text { strategic alliance }\end{array}$ & 4.9 & 29.3 & 61.0 & 4.9 & $2.66(0.66)$ & 17 \\
\hline 16 & $\begin{array}{l}\text { We lobbied government for } \\
\text { suitable policies }\end{array}$ & 17.1 & 24.4 & 46.3 & 12.2 & $2.54(0.93)$ & 22 \\
\hline 17 & $\begin{array}{l}\text { We reached out to our } \\
\text { customers frequently }\end{array}$ & 2.4 & 17.1 & 63.4 & 17.1 & $2.95(0.67)$ & 8 \\
\hline 18 & $\begin{array}{l}\text { We engaged in COVID-19 } \\
\text { prevention measures }\end{array}$ & 0.0 & 4.9 & 53.7 & 41.5 & $3.37(0.58)$ & 2 \\
\hline 19 & $\begin{array}{l}\text { We continuously discuss with } \\
\text { our staffs to overcome the } \\
\text { current problem }\end{array}$ & 0.0 & 4.9 & 46.3 & 48.8 & $3.44(0.59)$ & 1 \\
\hline \multirow[t]{2}{*}{20} & $\begin{array}{l}\text { We try to strengthen the overall } \\
\text { supply chain }\end{array}$ & 0.00 & 12.2 & 68.3 & 19.5 & $3.07(0.56)$ & 7 \\
\hline & Social response & & & & & & \\
\hline 21 & $\begin{array}{l}\text { Maintained social } \\
\text { distancing at work }\end{array}$ & 0.00 & 7.30 & 73.2 & 19.5 & $3.12(0.51)$ & 4 \\
\hline 22 & Redesigned the workplace & 19.5 & 26.8 & 41.5 & 12.2 & $2.46(0.95)$ & 26 \\
\hline & $\begin{array}{l}\text { Provided Personal protection } \\
\text { equipment (PPE) }\end{array}$ & 26.8 & 29.3 & 24.4 & 19.5 & $2.37(1.09)$ & 28 \\
\hline & $\begin{array}{l}\text { Disinfect our workplace } \\
\text { regularly }\end{array}$ & 4.9 & 31.7 & 41.5 & 22.0 & $2.80(0.84)$ & 11 \\
\hline 25 & Paid salaries/wages regularly & 2.4 & 12.2 & 53.7 & 31.7 & $3.15(0.73)$ & 3 \\
\hline & $\begin{array}{l}\text { Continued paying fringe } \\
\text { benefits to staffs }\end{array}$ & 24.4 & 39.0 & 26.8 & 9.8 & $2.22(0.94)$ & 33 \\
\hline & $\begin{array}{l}\text { Staffs/worker maintained good } \\
\text { emotional and physical health }\end{array}$ & 0.00 & 9.8 & 70.7 & 19.5 & $3.10(0.54)$ & 5 \\
\hline 28 & Provided flexible work schedule & & 14.6 & 39.0 & 39.0 & $3.10(0.92)$ & 6 \\
\hline \multirow[t]{2}{*}{29} & Provided COVID insurance & 41.5 & 22.0 & 9.8 & 26.8 & $2.22(1.25)$ & 34 \\
\hline & & $\begin{array}{l}\text { Highly } \\
\text { Decrease }\end{array}$ & Decrease & Increase & $\begin{array}{l}\text { Highly } \\
\text { Increase }\end{array}$ & $\begin{array}{l}\text { Mean } \\
\text { (Std. } \\
\text { Deviation) }\end{array}$ & \\
\hline \multicolumn{8}{|c|}{ SMEs' perception on post COVID-19 } \\
\hline & Your future sales & 2.4 & 48.8 & 43.9 & 4.9 & $2.51(0.64)$ & 24 \\
\hline & Your future production & 7.3 & 22.0 & 63.4 & 7.3 & $2.71(0.72)$ & 15 \\
\hline & $\begin{array}{l}\text { Availability of raw material } \\
\text { supply in future }\end{array}$ & 4.9 & 36.6 & 48.8 & 9.8 & $2.63(0.73)$ & 20 \\
\hline & $\begin{array}{l}\text { Availability of required labour } \\
\text { supply in future }\end{array}$ & 4.9 & 22.0 & 51.2 & 22.0 & $2.90(0.80)$ & 10 \\
\hline & Your staff number in future & 2.4 & 29.3 & 56.1 & 12.2 & $2.78(0.69)$ & 13 \\
\hline
\end{tabular}




\begin{tabular}{|c|c|c|c|c|c|c|c|}
\hline & & $\begin{array}{l}\text { Highly } \\
\text { Unlikely }\end{array}$ & Unlikely & Likely & $\begin{array}{l}\text { Highly } \\
\text { Likely }\end{array}$ & $\begin{array}{l}\text { Mean } \\
\text { (Std. } \\
\text { Deviation) }\end{array}$ & \\
\hline 35 & $\begin{array}{l}\text { Change your business model } \\
\text { in future }\end{array}$ & 17.1 & 24.4 & 46.3 & 12.2 & $2.54(0.92)$ & 23 \\
\hline 36 & $\begin{array}{l}\text { Availability of sufficient capital/ } \\
\text { loan in future }\end{array}$ & 12.2 & 48.8 & 36.6 & 2.4 & $2.29(0.72)$ & 31 \\
\hline 37 & Government support in future & 36.6 & 39.0 & 19.5 & 4.9 & $1.93(0.88)$ & 41 \\
\hline \multirow[t]{3}{*}{38} & New business opportunities & 14.6 & 31.7 & 46.3 & 7.3 & $2.46(0.84)$ & 27 \\
\hline & & $\begin{array}{l}\text { Highly } \\
\text { Dissatisfied }\end{array}$ & Unsatisfied & Satisfied & $\begin{array}{l}\text { Highly } \\
\text { Satisfied }\end{array}$ & $\begin{array}{l}\text { Mean } \\
\text { (Std. } \\
\text { Deviation) }\end{array}$ & \\
\hline & \multicolumn{7}{|c|}{ Government's response to COVID-19 } \\
\hline 39 & $\begin{array}{l}\text { Government extended loan } \\
\text { repayment policy }\end{array}$ & 24.4 & 36.6 & 34.1 & 4.9 & $2.20(0.87)$ & 35 \\
\hline 40 & $\begin{array}{l}\text { Government subsidize interest } \\
\text { loan }\end{array}$ & 19.5 & 46.3 & 29.3 & 4.9 & $2.20(0.81)$ & 36 \\
\hline 41 & $\begin{array}{l}\text { Budget speech for fiscal year } \\
2020 / 2021\end{array}$ & 31.7 & 31.7 & 36.6 & 0.0 & $2.05(0.83)$ & 37 \\
\hline 42 & $\begin{array}{l}\text { Government's business } \\
\text { promotion measures }\end{array}$ & 46.3 & 39.0 & 14.6 & 0.0 & $1.68(0.72)$ & 43 \\
\hline 43 & $\begin{array}{l}\text { Government policy to tax rebate } \\
\text { for increasing export }\end{array}$ & e34.1 & 36.6 & 26.8 & 2.4 & $1.98(0.85)$ & 40 \\
\hline
\end{tabular}

Note. Survey 2020 and authors calculations

(i) The estimates are based on 41 respondents,

(ii) Figures in parenthesis are standard deviation,

(iii) there may be few figures-rounding errors.

Table 2

Mean Values of Responses by Major Areas

\begin{tabular}{ll}
\hline Area & Mean \\
\hline Social response & $2.73(0.53)$ \\
Firm's respond to COVID-19 & $2.65(0.34)$ \\
SMEs' perception on post COVID-19 & $2.53(0.42)$ \\
Current business challenges & $2.51(0.57)$ \\
Government's respond to COVID-19 & $2.02(0.64)$ \\
\hline
\end{tabular}

Note.Survey 2020 and authors calculations. Figures in parenthesis are standard deviation.

Table 2 exhibits the mean values of responses by major areas of the study: (i) Current business challenges, (ii) Firm's respond to COVID-19, (iii) Social response, (iv) SMEs' perception on post COVID-19, and (v) Government's response to COVID-19. The mean value ranges from 2.02 to 2.73 for all five 
areas. As per the mean values, the Nepalese SMEs gave first priority to serve their workers and, second, they quickly and responsibly respond to challenges of COVID-19. They are hopeful for their future business environment in third and they worried about current business challenges in the fourth. On the contrary, the Nepalese SMEs are not optimistic to get good responses from the government to recover the better business environment.

Based on the data given in Table 2, matched t-tests are performed to determine what areas are more important to COVID-19 crisis, which is shown in Table 3. To determine whether or not these observed differences indicate different rankings of COVID-19 solution needs within each group. The respondents distinctively rank the COVID-19 needs of all five areas. Social response issues are perceived to be most important followed by SMEs' perception on post COVID-19 and current business challenges. Government's response to COVID-19 issues perceived to be the least important in relative terms.

Table 3

Matched t-test Result for Comparisons of Major Areas

\begin{tabular}{llll}
\hline Area compared & $\begin{array}{l}\text { Mean } \\
\text { difference }\end{array}$ & t-value & p-value \\
\hline Social response and Firm's response to COVID-19 & 0.07 & 0.80 & .429 \\
Social response and SMEs' perception on post COVID-19 & 0.20 & 2.38 & .022 \\
Social response and Current business challenges & 0.22 & 1.70 & .096 \\
Social response and Government's respond to COVID-19 & 0.71 & 5.54 & .000 \\
Firm's respond to COVID-19 and SMEs' perception on post & 0.12 & 1.46 & .153 \\
COVID-19 & & & \\
Firm's respond to COVID-19 and Current business challenges & 0.15 & 1.50 & .140 \\
Firm's respond to COVID-19 and Government's respond to & 0.63 & 5.51 & .000 \\
COVID-19 & & & \\
SMEs' perception on post COVID-19 and Current business & 0.02 & .17 & .868 \\
challenges & & & \\
SMEs' perception on post COVID-19 and Government's & 0.51 & 4.55 & .000 \\
respond to COVID-19 & & & \\
$\begin{array}{l}\text { Current business challenges and Government's respond to } \\
\text { COVID-19 }\end{array}$ & 0.49 & 3.26 & .002 \\
\hline
\end{tabular}

Note.Survey 2020 and authors calculations

Figure 1 summarises these results in graphical form of Table 3 . Each area is marked in a box, and the mean scores are reported. Significant differences for respondents are represented by placing at different levels in the figure. As indicated in earlier tests, social response issues represent the highest ranked area. The SMEs' perception on post COVID-19 and current business challenges are clearly considered the second most important areas. The government's response to COVID-19 issue is considered as the lowest importance to cope with COVID-19 crisis. 
Level 1 Firm's respond to COVID-19 (2.65)

Level 2

SMEs' perception on post

COVID-19

(2.02)
Current business challenges

(2.51)

Level 3

Government's respond to

COVID-19

(2.02)

Figure 1: Hierarchy of Major Areas

\section{Conclusions and Implications}

This study has attempted to identify some of the key issues and challenges of Nepalese SMEs amidst COVID-19. The pandemic is still disrupting businesses, economy and lives. While keeping social distance and taking safety measures businesses tend to reopen but the impact is so overwhelming that SMEs are not able to see through this crisis. The impact is huge, loss of sales and cash flow is immediate but the consequences are severe and mid-term in nature. Despite the challenges posed to Nepalese SMEs, most SMEs are paying their workers and keeping them so far. Their resilience is reflected in their pursuit to continue their business by keeping the people, changing their business models and continuing good relationships with their clients. Despite the challenges, they are optimistic to post pandemic situations and foresee new business opportunities. However, they are not satisfied with the government's efforts at the time of crisis. They expect the possibility of using technology to leverage future prospects. Their entrepreneurial thrust will take them beyond the crisis. They need innovation and explore new market opportunities.

The chaos and uncertainty of the pandemic is not over yet and it is still difficult to see through this crisis. However, one has to prepare strategies to get through this crisis. Every crisis also gives new opportunities; what they need is to invest in technology, market development, innovation, operational efficiency and building strong consumer bases.

The world has witnessed the shift on consumer behaviours; working from home, online shopping, online education and entertainments, which will have profound effects on products and services design and delivery. SMEs need to invest in exploring new markets potentials both within Nepal and abroad. SMEs can diversify the market by identifying emerging markets that will bring additional sales revenues. 
SMEs need to invest in technology to capitalise the growth of e-commerce. They need to observe market shifts and identify the opportunity and make their products and services available through e-commerce. Mobile applications, social media and content marketing should be streamlined.

SMEs need to build resilience by strengthening their entire supply chain and improving their operational efficiencies. Cutting costs and generating cash flow would give some leverage to get back to business.

The role of government is inevitable in safeguarding SMEs and building their resilience through its fiscal and monetary policies along with long-term trade facilitation services. Stimulus plan would help SMEs gain some confidence.

The impact of COVID-19 is yet to realise as partial lockdown measures continues and SMEs are finding difficulties to operate. Periodic assessment should be done to understand the real time situation of the SMEs. It would be also interesting to see in future study the impact of government's interventions in response to COVID-19.

\section{References}

Central Bureau of Statistics. (2019). National economic census report no. 1. Kathmandu: Author.

Chitrakar, S. (2019). Market and entrepreneurial orientation of Nepalese small and medium enterprises (SMEs) ( Unpublished doctoral dissertation). Tribhuvan University, Nepal.

Gibbens, E. (2020). Helping small businesses navigate through Covid 19. Retrieved from wwwonitary Fund. (2020, June). A crisis like no other, An uncertain recovery. World Economic Outlook Update. Author.

International Monetary Fund. (2020). World economic outlook update. Author.

Isenberg, D., Onyemah, V., \& Mulcahy, E. E. (2020). 5 ways entrepreneurs and SMEs can build resilience in a coronavirus economy. World Economic Forum.

Retrieved from www.weforum.org/agenda/2020/05/entrepreneurs-smes-resiliencecoronavirus-economy

Ministry of Finance, Government of Nepal. (2020). Economic survey 2019/20. Kathmandu: Author.

Nepali Times. (2020, July 12). Retrieved on August 23, 2020https://www.nepalitimes. com/latest/nepal-internet-use-increases-by-35-during-lockdown

OCED. (2020, August 22). Coronavirus (Covid-19): SME policy responses. Retrieved from www.oced.org

Rajagopaul, A., Magwentshu, N., \& Kalidas, S. (2020). How South African SMEs can survive and thrive post Covid-19: Providing the right support to enable SME growth now and beyond the ciris. McKinsey \& Company.

Shrestha, S. (2020). What are the challenges for Nepali SMEs amidst Covid 19 crisis. Zurich: Business \& Finance Consulting. Retrieved from https://bfconsulting.com/ what-are-the-challenges-for-nepali-smes-amidst-covid-19-crisis/ 
Shretha, S. (2020). Sustainable organisations to emerge as leaders during the COVID-19. International Journal of Entrepreneurship and Economic Issues, 4(1), 65-69.

United Nations Development Programme. (2020). Rapid assessment of social economic impact of Covid 19 in Nepal. Lalitpur:

World Bank. (2020). Nepal development update: Post-pandemic Nepal - Charting a resilient recovery and future growth directions. Washington: World Bank Group.

World Health Organisation. (2020, August). Retrieved from

https://covid19. who.int/?gclid=EAlalQobChMIxbbij7Or6w/Vj30rCh3SCAdyEAAYASABE gJrVvD_BwE.

\section{Funding}

The author received no funding or financial support in carrying out the research.

Conflict of interest

The authors claim that they have no conflict of interest in the research work. 